\title{
BTS guidelines for the management of pleural infection
}

\author{
C W H Davies, F V Gleeson, R J O Davies, on behalf of the BTS Pleural Disease Group, \\ a subgroup of the BTS Standards of Care Committee
}

Thorax 2003;58(Suppl II):ii 18-ii28

$\mathrm{T}$ here is great variation worldwide in the management of patients with pleural infection, and approaches differ between physicians. ${ }^{1-14}$ In the UK up to $40 \%$ of empyema patients come to surgery due to failed catheter drainage ${ }^{4}$ and, overall, $20 \%$ of patients with empyema die. ${ }^{4}$ The process of rapid evaluation and therapeutic intervention appears to reduce morbidity and mortality, as well as health care costs.

This paper presents the results of a peer reviewed systematic literature review, combined with expert opinion, of the preferred management of pleural infection. The clinical guidelines generated from this process are shown in fig 1 . The guidelines are aimed predominantly at physicians involved in general and respiratory medicine, and specifically do not cover in detail the complex areas of surgical management or the management of post pneumonectomy empyema.

\section{HISTORICAL PERSPECTIVE, PATHOPHYSIOLOGY AND BACTERIOLOGY OF PLEURAL INFECTION}

This section provides background information for reference, interest, and to set the management guidelines in context.

\subsection{Historical perspective}

Pleural infection was first described by Hippocrates in 500BC. Open thoracic drainage was the only treatment for this disorder until the 19th century when closed chest tube drainage was first described but not adopted. ${ }^{15}$ This technique became widely practised during an influenza epidemic in 1917-19 when open surgical drainage was associated with a mortality rate of up to $70 \%{ }^{16}$ This high mortality was probably due to respiratory failure produced by the large open pneumothorax left by open drainage. ${ }^{16}$ This was particularly true of Streptococcus haemolyticus infections which produce streptokinase and probably reduce adhesion formation. ${ }^{16} \mathrm{~A}$ military commission investigated this high mortality rate and produced recommendations that remain the basis for treatment today. They advocated adequate pus drainage with a closed chest tube, avoidance of early open drainage, obliteration of the pleural space, and proper nutritional support. These changes reduced the mortality rate to $3.4 \%$ during the later stages of the epidemic.

The introduction of antibiotics both reduced the incidence of empyema and changed its bacteriology. Before antibiotics $60-70 \%$ of cases were caused by Streptococcus pneumoniae, which now accounts for about $10 \%$ of culture positive cases. ${ }^{17}$ The prevalence of Staphylococcus aureus rose and the development of staphylococcal resistance in the $1950 \mathrm{~s}$ increased complications and mortality. ${ }^{18}$ More recently, the reported prevalence of anaerobic infections ${ }^{14} 1820$ and Gram negative organisms ${ }^{14} 20$ has risen. Intrapleural fibrinolytic therapy was first introduced in $1949,{ }^{21}$ but the impure agents used caused adverse reactions. Most recently, thoracoscopic surgery has introduced the early use of video assisted thoracoscopic (VATS) pleural debridement. ${ }^{9}$

\subsection{Pathophysiology of pleural infection}

Pneumonia leads to about 50000 hospital admissions each year in the UK. ${ }^{22}$ Up to $57 \%$ of patients with pneumonia develop pleural fluid ${ }^{2324}$ and there are about 60000 cases of pleural infection in the USA per year. ${ }^{3}$ A significant proportion of cases are related to community and hospital acquired pneumonia, or are secondary to iatrogenic causes. Pleural infection may also develop without evidence of pneumonia-so called primary empyema. Most forms of pleural infection represent a progressive process that transforms a fluid self-resolving parapneumonic pleural effusion into a complicated multiloculated fibrotic and purulent collection which significantly impairs respiratory reserve and is only amenable to surgical drainage.

\subsection{Normal pleural fluid physiology}

In health, the volume of pleural fluid in humans is small $(<\mathrm{lml})$, forming a film about $10 \mu \mathrm{l}$ thick between the visceral and parietal pleural surfaces. ${ }^{25}$ Pleural fluid contains protein at concentrations similar to the interstitial fluid, a small number of cells (predominantly mesothelial cells, macrophages and lymphocytes), and some large molecular weight proteins such as lactate dehydrogenase (LDH). Compared with serum, pleural fluid in health also contains higher levels of bicarbonate, lower levels of sodium, and similar levels of glucose. ${ }^{26}$ These parameters change when disease processes affecting the adjacent lung or vascular tissue activate an immune response.

Water and small molecules pass freely between mesothelial cells, while larger particles may be transported by cytoplasmic transport mechanisms or via the pleurolymphatic communication. The pleurolymphatic communication is poorly documented but probably consists of a series of stomas in selected areas of pleura overlying connective tissue and a series of dilated lymphatic channels with regulatory valves. ${ }^{25}$

\subsection{Pleural effusion development with pneumonia}

The development of empyema in association with pneumonia is a progressive process that moves from a simple exudate to a fibrinopurulent stage and later to an organising stage with scar tissue formation. ${ }^{27}$ The stage when the pleural fluid is a straightforward exudate is often called a "simple parapneumonic effusion". The early fibrinopurulent stage when the pleural fluid has developed 


\section{Diagnostic algorithm for the management of patients with pleural infection}

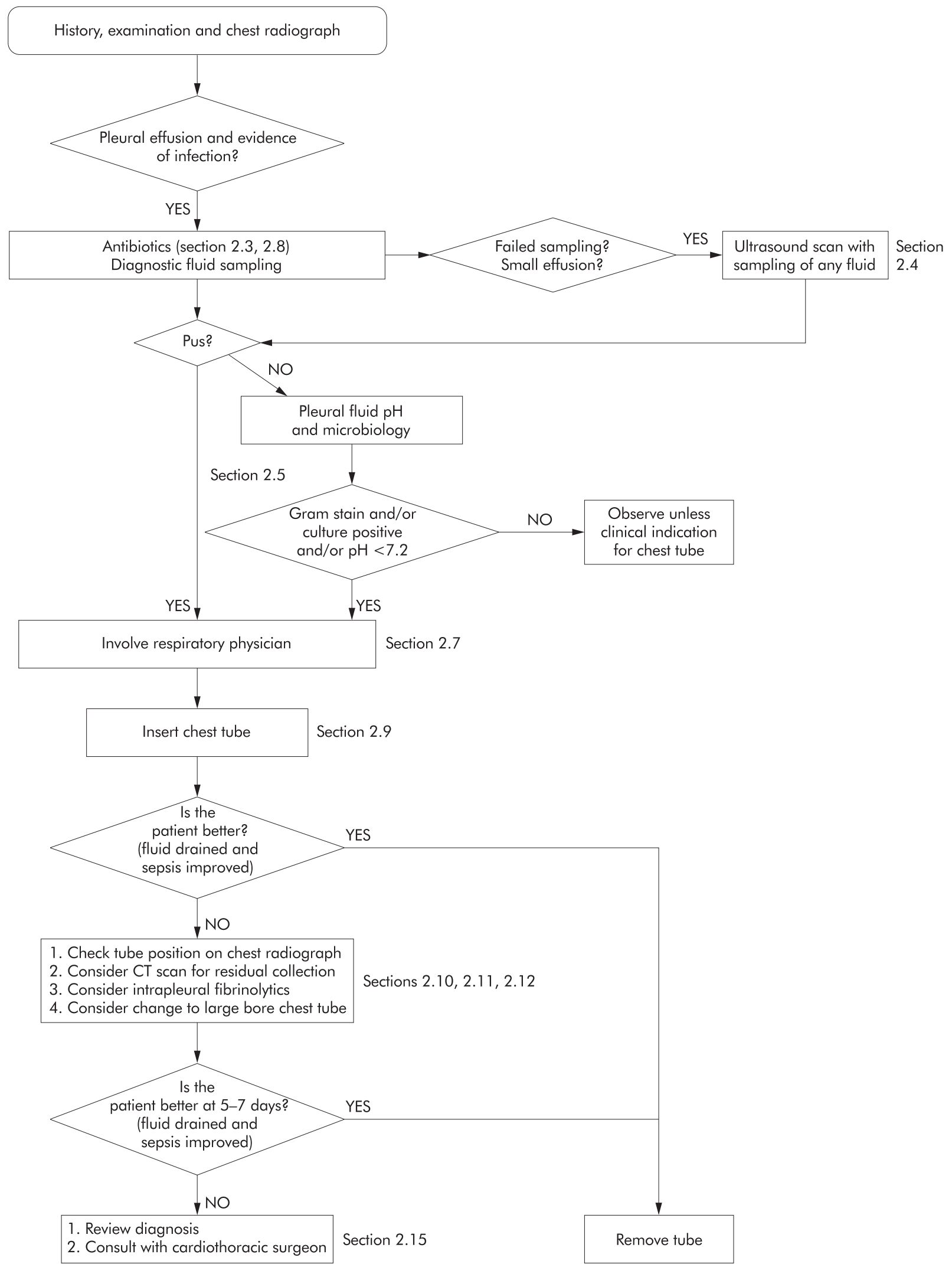

Figure 1 Flow diagram describing the management of pleural infection. 
Table 1 Characteristics of parapneumonic pleural effusions

\begin{tabular}{|c|c|c|c|}
\hline Stages & Macroscopic appearance & Pleural fluid characteristics & Comments \\
\hline Simple parapneumonic & Clear fluid & $\begin{array}{l}\mathrm{pH}>7.2 \\
\mathrm{LDH}<1000 \mathrm{IU} / \mathrm{I} \\
\text { Glucose }>2.2 \mathrm{mmol} / / \\
\text { No organisms on culture or Gram stain }\end{array}$ & $\begin{array}{l}\text { Will usually resolve with antibiotics alone. } \\
\text { Perform chest tube drainage for symptom relief if } \\
\text { required }\end{array}$ \\
\hline Complicated parapneumonic & Clear fluid or cloudy/turbid & $\begin{array}{l}\mathrm{pH}<7.2 \\
\mathrm{LDH}>1000 \mathrm{IU} / \mathrm{I} \\
\text { Glucose }>2.2 \mathrm{mmol} / \mathrm{I} \\
\text { May be positive Gram stain/culture }\end{array}$ & Requires chest tube drainage \\
\hline Empyema & Frank pus & May be positive Gram stain/culture & $\begin{array}{l}\text { Requires chest tube drainage } \\
\text { No additional biochemical tests necessary on } \\
\text { pleural fluid (do not measure } \mathrm{pH} \text { ) }\end{array}$ \\
\hline
\end{tabular}

$\mathrm{LDH}=$ lactate dehydrogenase

features of infection but is not yet overtly purulent is termed a "complicated parapneumonic effusion". Frank pus is termed "empyema". The features of these three stages are summarised in table 1 .

In the early exudative stage there is fluid movement into the pleural space due to increased capillary vascular permeability, accompanied by the production of proinflammatory cytokines. ${ }^{28}$ These produce active changes in the pleural mesothelial cells to facilitate fluid entry into the pleural cavity. Initially the fluid is a free flowing exudate characterised by a low white cell count, a lactate dehydrogenase (LDH) level less than half that in the serum, normal pH and glucose levels, and does not contain bacterial organisms. ${ }^{64} 29-32$ Treatment with antibiotics at this stage is likely to be adequate and most effusions of this type do not require chest tube drainage. ${ }^{6432}$

\subsection{Development of complicated parapneumonic effusion and empyema}

Parapneumonic effusions in the exudative stage progress to the fibrinopurulent stage with increasing fluid accumulation and bacterial invasion across the damaged endothelium. Bacterial invasion accelerates the immune reaction, promoting further migration of neutrophils and also activation of the coagulation cascade leading to increased procoagulant and depressed fibrinolytic activity. ${ }^{283}$ This favours fibrin deposition and allows septations to form within the fluid. Neutrophil phagocytosis and bacterial death fuel the inflammatory process by the release of more bacteria cell wall derived fragments and proteases. ${ }^{28}$ This combination of events leads to increased lactic acid production, associated with a fall in pleural fluid $\mathrm{pH}^{34}$ accompanied by increased glucose metabolism and a rise in LDH levels due to leucocyte death leading to the characteristic biochemical features of a fibrinopurulent collection $(\mathrm{pH}$ $<7.20$, glucose $<2.2 \mathrm{mmol} / \mathrm{l}, \mathrm{LDH}>1000 \mathrm{IU} / \mathrm{l})$.

The organising stage follows with the proliferation of fibroblasts. ${ }^{28}$ As a solid fibrous pleural peel replaces the soft fibrin, the re-expansion of lung is prevented, impairing lung function and creating a persistent pleural space with continuing potential for infection.

\subsection{Bacteriology of pleural infection}

Currently, aerobic organisms are those most frequently identified from empyemas. Gram positive organisms from the streptococcal species, including the $S$ milleri group of organisms, and Staphylococcus aureus are most commonly found. ${ }^{10} 11132035-47$ Most patients with $S$ aureus have postoperative or nosocomial empyemas or are immunocompromised. ${ }^{42} S$ aureus is seen frequently in patients following trauma and surgery. ${ }^{38}$ Gram negative organisms are also the most commonly found aerobic bacteria in pleural infection, including Escherichia coli, Pseudomonas spp, Haemophilus influenzae, and Klebsiella spp. ${ }^{11} 132036374042-4446-48$ These organisms are commonly part of mixed growths with other Gram negative organisms or with anaerobes ${ }^{11} 20383941-45$ and rarely occur in isolation.
The frequency of anaerobic isolates is rising and anaerobes may be present in up to $76 \%$ of cases. ${ }^{18} 363749$ However, most series report anaerobes in $12-34 \%$ of positive pleural fluid cultures. ${ }^{41011} 13203941434447$ Anaerobes may cause empyema without other aerobic co-pathogens in about 14\% of culture positive cases. ${ }^{10} 18204144$ Infections with anaerobes are more likely to have an insidious clinical onset, ${ }^{36}$ with less fever, greater weight loss, and are more common following possible aspiration pneumonia and with poor dental hygiene. ${ }^{36}$

\section{IDENTIFICATION AND RADIOLOGICAL ASSESSMENT OF PNEUMONIA ASSOCIATED PLEURAL EFFUSION}

This section presents the detail of the literature evidence and expert opinion behind the guideline presented in fig 1 .

\subsection{Identification}

A pleural effusion may be obvious on the chest radiograph ${ }^{50}$ and the co-existence of pulmonary infiltrates and fluid should alert the clinician to the possibility of a parapneumonic collection. Empyema should be suspected in patients who are failing to respond to appropriate antibiotic therapy. Lateral chest radiographs may confirm pleural fluid not suspected on the posteroanterior chest radiograph. ${ }^{24}$ Ultrasound scanning, which is now readily available, is the preferred investigation and enables exact location of any fluid collection and allows guided diagnostic aspiration if required..$^{50}$

Occasionally, pleural sepsis is caused by oesophageal rupture and this diagnosis should be suspected in patients who develop a pleural effusion soon after significant retching or vomiting. Oesophageal imaging and the detection of an oesophageal leak should prompt immediate referral to a surgeon with expertise in the management of oesophageal rupture. $^{43}$

\subsection{Radiological assessment}

Ultrasound may help to identify exudative pleural effusions; in a study of 320 cases of pleural effusion ${ }^{52}$ all echogenic effusions were caused by exudates and homogeneous echogenic effusions were due to either empyema or haemorrhage. In a review of both ultrasound and computed tomographic (CT) appearances in a group of patients with parapneumonic effusion requiring drainage, the appearances at ultrasound (septations, echogenicity, fig 2) did not correlate with the length of history, presence or absence of purulence, or the biochemical staging of pleural infection, but pleural thickness on contrast enhanced CT scanning was greater in those with frankly purulent effusions..$^{53}$

In cases of diagnostic difficulty, contrast enhanced CT scanning may help to differentiate pleural empyema from a parenchymal lung abscess. Empyemas are usually lenticular in shape and compress the lung parenchyma, while lung abscesses often have an indistinct boundary between the lung parenchyma and collection. ${ }^{545}$ The "split pleura" sign, caused 

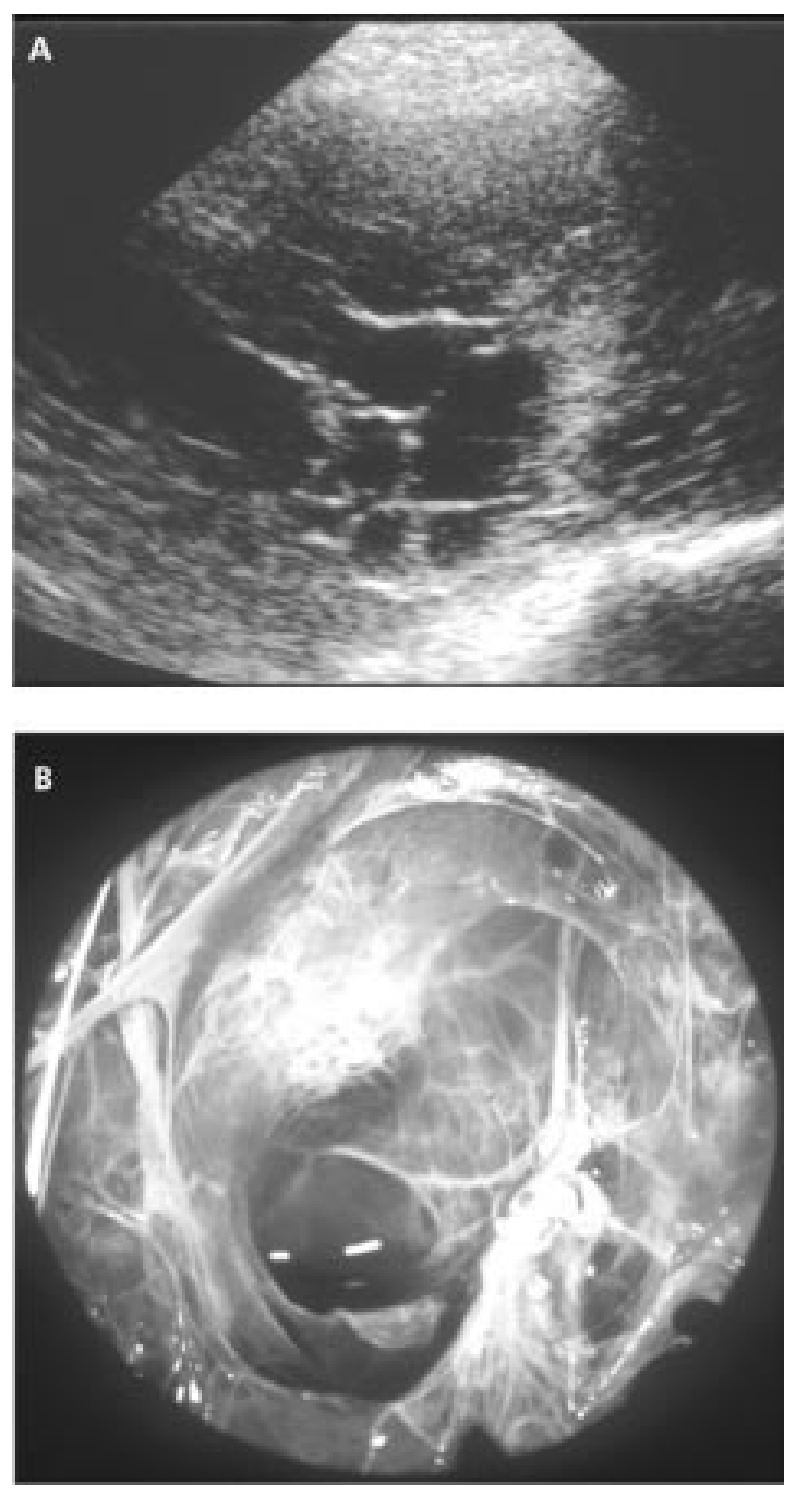

Figure 2 (A) Typical pleural ultrasound appearance of pleural infection and (B) the macroscopic appearances of pleural fibrinous septation. The pleural ultrasound image $(A)$ shows the pleural space divided into a multi-septated collection with varying echogenic appearances within the divided fluid indicating varying degrees of fluid purulence. The pleural photograph (B) is taken at thoracoscopy and shows the macroscopic appearance of fibrinous pleural septation, in this case an infected malignant pleural effusion.

by enhancement of both parietal and visceral pleural surfaces (fig 3), and their separation in empyema is characteristic of a pleural collection. Pleural thickening is seen in $86-100 \%$ of empyemas $^{56-58}$ and $56 \%$ of exudative parapneumonic effusions. ${ }^{56}$ The absence of pleural thickening indicates a likely simple parapneumonic effusion. ${ }^{56}$ In pleural infection there is pleural enhancement with CT contrast studies, ${ }^{57}$ and the extrapleural subcostal fat is of increased attenuation..$^{55-58}$

\subsection{Which patients with a parapneumonic effusion need diagnostic pleural fluid sampling?}

- All patients with a pleural effusion in association with sepsis or a pneumonic illness require diagnostic pleural fluid sampling. [C]

It is currently impossible to clinically differentiate patients with a complicated parapneumonic effusion requiring chest tube drainage from those with a simple effusion that may

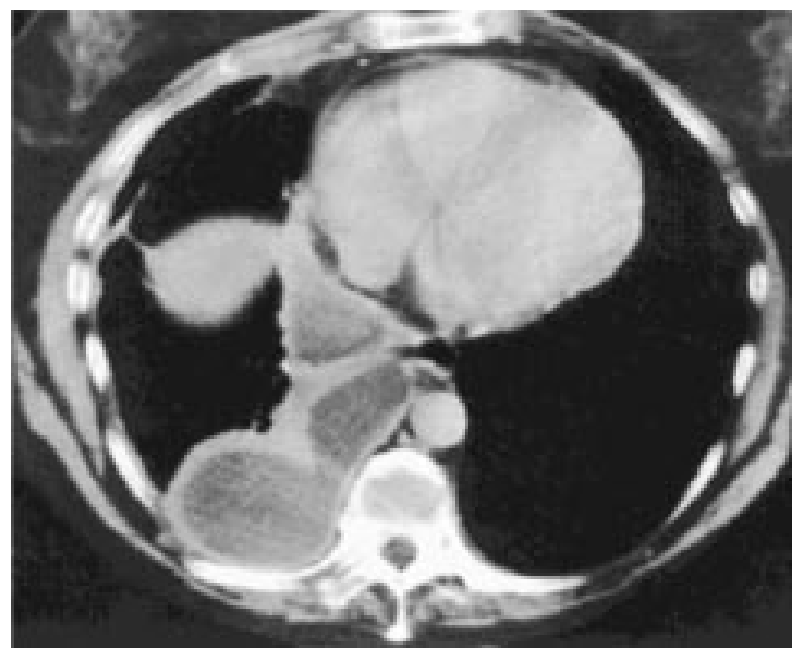

Figure 3 Typical contrast enhanced CT appearances of pleural empyema. The image shows a multiloculated pleural collection forming separate lenticular pleural opacities. The "split pleura sign" with enhancing pleural tissue visible on both the visceral and parieta pleural surfaces is shown. Note that the septation within individual locules that is seen on ultrasound (fig 2A) is not seen on CT scanning.

resolve with antibiotics alone, and there are no specific data relating to which patients with a parapneumonic effusion can be managed without diagnostic pleural fluid sampling. There are no differences in age, white cell count, peak temperature, incidence of pleural pain, or the degree of radiological infiltrate between those requiring chest tube drainage for resolution of symptoms and those who may resolve with antibiotics alone. ${ }^{24}$ In patients with pneumococcal pneumonia the development of parapneumonic effusions may be associated with a longer duration of symptoms and the presence of bacteraemia, ${ }^{23}$ but the majority of these patients will have a "simple parapneumonic effusion" and will not require chest tube drainage. Similarly, there are no reliable clinical ${ }^{59}{ }^{60}$ or radiological ${ }^{59}$ characteristics that will predict which patients with pleural infection will come to surgery.

Pleural fluid characteristics remain the most reliable diagnostic test to guide management ${ }^{62293260-63}$ and diagnostic pleural fluid sampling is therefore recommended in all patients with a pleural effusion in association with a pneumonic illness or recent chest trauma or surgery. Patients in an intensive care (ICU) setting frequently develop pleural effusions that are not caused by pleural infection. ${ }^{64}$ It is probably safe to observe such patients with hypoalbuminaemia, heart failure, or atelectasis who are at low risk of infection while treating the underlying condition. ${ }^{64}$ Pleural fluid should be sampled if there are features of sepsis, possibly under ultrasound guidance if patients are receiving positive pressure ventilation.

\subsection{Patients with a small pleural effusion or who have} failed diagnostic pleural fluid sampling

- In the event of a small effusion or a failed previous attempt at pleural fluid sampling, an ultrasound scan and image guided fluid sampling is recommended. [C]

- Pleural effusions with maximal thickness $<10 \mathrm{~mm}$ on ultrasound scanning can be observed, with pleural fluid sampling if the effusion enlarges. [C]

In the event of a small effusion, failure of an attempt to gather a pleural fluid sample, or an inexperienced operator, an ultrasound scan and image guided pleural fluid sampling is simple and will reduce patient discomfort. ${ }^{50}$ Small effusions of 
$<10 \mathrm{~mm}$ thickness on a decubitus chest radiograph will usually resolve with antibiotics alone..$^{24}{ }^{32}$ As ultrasound is used in preference to decubitus chest radiography in the UK, it seems reasonable to observe any effusion where maximal thickness is $<10 \mathrm{~mm}$ on ultrasound scanning. An increase in the size of the effusion should warrant re-evaluation and a diagnostic pleural fluid sample if clinically indicated.

\subsection{When to use chest tube drainage in pleural infection}

- Patients with frankly purulent or turbid/cloudy pleural fluid on sampling should receive prompt pleural space chest tube drainage. [B]

The presence of frankly purulent or turbid/cloudy fluid on pleural aspiration indicates the need for prompt chest tube drainage. .4 $326263^{63}$ Purulent fluid is more frequent in patients who fail chest tube drainage and require surgery or in those who die. ${ }^{59}$

- The presence of organisms identified by Gram stain
or culture from non-purulent pleural fluid samples
indicates that pleural infection is established and indicates that pleural infection is established
should lead to prompt chest tube drainage. [B]

The presence of organisms identified by positive Gram staining indicates bacterial invasion and implies progression from a simple effusion into empyema and hence the need for chest tube drainage. ${ }^{24} 326263$ Some frankly purulent or culture positive parapneumonic effusions due to pneumococcus may resolve without chest tube drainage, ${ }^{2360}$ but clinicians should be aware of the common co-existence of anaerobes not readily cultured in the laboratory before making a therapeutic decision not to drain a frank empyema.

- Pleural fluid pH should be assessed in all nonpurulent, possibly infected effusions. [B]

- $\mathrm{pH}<7.2$ indicates chest tube drainage is required. [B]

- Parapneumonic effusions that do not fulfil these criteria for chest tube drainage should be treated with antibiotics alone provided clinical progress is good. [B]

- Poor clinical progress during treatment with antibiotics alone should lead to prompt patient review and probably chest tube drainage. [B]

Parapneumonic pleural effusions are inflammatory exudates dominated by polymorphonuclear leucocytes. The absolute protein values are of no value in determining the likelihood of spontaneous resolution of the effusion or chest tube drainage requirements. ${ }^{6431}{ }^{60}$ The pleural fluid leucocyte count shows a wide variation in values between simple effusions and frankly purulent empyemas, ${ }^{32}$ and a predominance of lymphocytes in an exudate should raise the possibility of malignancy or tuberculosis. Some non-purulent collections will show biochemical evidence of infection and are likely to need chest tube drainage for resolution of sepsis..$^{24-32}{ }^{34}$ 61-63 The development of a pleural fluid acidosis associated with a rising pleural level of LDH and a falling glucose level are characteristic and constitute the biochemical criteria for pleural infection. $^{243263}$

These biochemical criteria have been reviewed in a systematic meta-analysis of the data justifying their use. ${ }^{63}$ This report showed that pleural fluid $\mathrm{pH}$ is the most useful index predicting the need for chest tube drainage and that the pleural LDH and glucose levels did not further improve diagnostic clarity. A pleural $\mathrm{pH}$ of about 7.2 was identified as best indicating the need for pleural drainage while previous studies had favoured a lower action threshold $(\sim 7.00) .{ }^{65}$ The increased mortality associated with older age and co-morbid disease should be an indication for more aggressive management and earlier chest tube drainage. ${ }^{63}$
Pleural fluid for $\mathrm{pH}$ should be collected anaerobically with heparin and then measured in a blood gas analyser. It is not advisable, and should not be necessary, to put frank pus through a blood gas analyser as this already indicates a need for chest tube drainage of the effusion. However, where there is uncertainty whether a turbid/cloudy fluid is infected, $\mathrm{pH}$ can be measured safely using a blood gas analyser. Extensive clinical experience of this technique, particularly in the US, has shown that it does not damage the blood gas analyser. Measurement of pleural fluid $\mathrm{pH}$ is unreliable when analysed by $\mathrm{pH}$ litmus paper or a $\mathrm{pH}$ meter, and these should not be considered as acceptable alternatives to a blood gas analyser. ${ }^{667}$ Physicians should be aware that lignocaine is acidic and can depress measured $\mathrm{pH}$ if given in large volumes or left in the same syringe used for local anaesthetic administration. $^{68}$

Parapneumonic pleural effusions that do not fulfil these criteria for chest tube drainage may be observed and are likely to resolve with antibiotics alone. However, some patients with an initial pleural $\mathrm{pH}$ of $>7.2$ will fail to resolve their sepsis syndrome and will require surgery despite chest tube drainage. ${ }^{59}$ These occasional cases confirm that, while pleural $\mathrm{pH}$ is specific in predicting the need for pleural drainage, it is less than $100 \%$ sensitive $e^{59}$ and does not accurately predict eventual need for surgery. ${ }^{59}{ }^{62}$ Unsatisfactory clinical progress therefore indicates the need for repeated pleural fluid sampling and possible chest tube drainage. When needle aspiration is straightforward, it may occasionally be possible to remove all the fluid at initial thoracocentesis. In some cases the fluid will not then return and no further intervention will be required.

\subsection{Other indications for chest tube drainage}

- Patients with a loculated pleural collection should receive earlier chest tube drainage. [C]

- Large non-purulent effusions should be drained by chest tube for symptomatic benefit. [C]

The presence of loculation on the chest radiograph or ultrascan is associated with a poorer outcome and may be an additional indication for early chest tube drainage. ${ }^{32}{ }^{61}{ }^{69}$ Larger pleural collections ( $>40 \%$ of the hemithorax) may be more likely to require surgery, ${ }^{49}$ and non-purulent effusions without acidosis can be drained with a chest tube if indicated for symptomatic benefit.

\subsection{Respiratory specialist}

- A respiratory physician or thoracic surgeon should be involved in the care of all patients requiring chest tube drainage for a pleural infection. [C]

In view of the substantial mortality associated with pleural infection, the small number of cases seen annually in a single centre and the need for prompt effective treatment, it is appropriate to focus the care of this disorder in specialist hands. Delay to chest tube drainage of the pleural space is probably associated with increased morbidity and duration of hospital stay, ${ }^{51338597071}$ and may lead to increased mortality. ${ }^{38}$ Misdiagnosis, inappropriate antibiotics, and inappropriate chest tube placement have been cited as important factors contributing to the progression of pleural infection. ${ }^{70}$

An appropriate physician requires the skills to identify patients for surgery and experience in assessing thoracic surgical risk as well as expertise in managing the substantial co-morbidity in these patients. A respiratory physician best combines these skills as well as having the advantage of an established liaison with a thoracic surgeon. In centres with thoracic surgery immediately available, care may be under a surgeon and a surgical opinion is appropriate after approximately 7 days in any patient not settling with drainage and antibiotics. 
Table 2 Illustrative antibiotic regimens for the initial treatment of culture negative pleural infection

\begin{tabular}{|c|c|c|}
\hline Origin of infection & Intravenous antibiotic treatment & Oral antibiotic treatment \\
\hline $\begin{array}{l}\text { Community acquired culture } \\
\text { negative pleural infection }\end{array}$ & $\begin{array}{l}\text { Cefuroxime } 1.5 \mathrm{~g} \text { tds iv + metronidazole } 400 \mathrm{mg} \text { tds orally or } \\
500 \mathrm{mg} \text { tds iv } \\
\text { Benzyl penicillin } 1.2 \mathrm{~g} \text { qds iv + ciprofloxacin } 400 \mathrm{mg} \text { bd iv } \\
\text { Meropenem } 1 \mathrm{~g} \text { tds iv + metronidazole } 400 \mathrm{mg} \text { tds orally or } \\
500 \mathrm{mg} \text { tds iv }\end{array}$ & $\begin{array}{l}\text { Amoxycillin } 1 \mathrm{~g} \mathrm{tds}+\text { clavulanic acid } 125 \mathrm{mg} \\
\text { tds } \\
\text { Amoxycillin } 1 \mathrm{~g} \mathrm{tds}+\text { metronidazole } 400 \mathrm{mg} \text { tds } \\
\text { Clindamycin } 300 \mathrm{mg} \text { qds }\end{array}$ \\
\hline $\begin{array}{l}\text { Hospital acquired culture negative } \\
\text { pleural infection }\end{array}$ & $\begin{array}{l}\text { Piperacillin }+ \text { tazobactam } 4.5 \mathrm{~g} \text { qds iv } \\
\text { Ceftazidime } 2 \mathrm{~g} \text { tds iv } \\
\text { Meropenem } 1 \mathrm{~g} \text { ts iv } \pm \text { metronidazole } 400 \mathrm{mg} \text { tds orally or } 500 \\
\mathrm{mg} \text { tds iv }\end{array}$ & Not applicable \\
\hline
\end{tabular}

No particular regimen is the single "ideal" choice. Drug doses should be appropriately adjusted in the presence of renal or hepatic failure.

\subsection{Antibiotics}

- All patients should receive antibiotics. [B]

- Where possible, antibiotics should be guided by bacterial culture results. [B]

- Where cultures are negative, antibiotics should cover community acquired bacterial pathogens and anaerobic organisms. [B]

- Hospital acquired empyema requires broader spectrum antibiotic cover. [B]

All patients should receive antibiotic therapy as soon as pleural infection is identified, and where possible, antibiotics should be chosen based on the results of pleural fluid culture and sensitivities. A significant proportion of both aerobes and anaerobes isolated from pleuropulmonary infections may be resistant to penicillin, ${ }^{1872} 73$ but beta-lactams remain the drugs of choice for pneumococcal ${ }^{74}$ and the $S$ milleri group infections. ${ }^{75}{ }^{76}$ Both penicillins and cephalosporins show good penetration of the pleural space,,$^{35778}$ and there is no need to administer antibiotics directly into the pleural space. Aminoglycosides should be avoided as they have poor penetration into the pleural space and may be inactive in the presence of pleural fluid acidosis. ${ }^{35} 79$

In the absence of positive culture results, antibiotics should be chosen to cover the likely organisms that may cause pleural infection. There are a considerable number of reasonable drug combinations and the chosen regimen should reflect whether the infection was contracted in the community or in hospital. The actual regimen choice should reflect local hospital policy.

In community acquired infection, empirical treatment with a second generation cephalosporin (e.g. cefuroxime) or an aminopenicillin (e.g. amoxycillin) will cover expected organisms such as Pneumococcus, Staphylococcus aureus, and Haemophilus influenzae. ${ }^{80} \mathrm{~A}$ beta-lactamase inhibitor or metronidazole should also be given because of the frequent co-existence of penicillin resistant aerobes and anaerobes. ${ }^{18} 7281$ Clindamycin can combine this spectrum into a single agent. Intravenous benzyl penicillin combined with a quinolone also has an appropriate spectrum and may be associated with a reduced incidence of Clostridium difficile diarrhoea.

There is evidence for a probable synergistic role of anaerobes with the $S$ milleri group of organisms ${ }^{82} 83$ and patients with these mixed infections have a higher mortality from empyema. ${ }^{76}$ Patients with an allergy to penicillin can be treated by clindamycin alone ${ }^{1880}$ or in combination with a cephalosporin. ${ }^{3}$ Chloramphenicol, carbapenems such as meropenem, third generation cephalosporins, and broad spectrum antipseudomonal penicillins such as piperacillin also have good anti-anaerobic activity and are alternative agents. ${ }^{73} 84$

Pleural effusions may occur in patients with Legionella pneumonia and are usually self-resolving. ${ }^{85}$ Legionella has rarely been reported as a cause of empyema ${ }^{86}$ and a macrolide should only be added in suspected cases. Similarly, pleural effusions may occur in $5-20 \%$ of patients with pneumonia due to Mycoplasma pneumoniae, ${ }^{87} 88$ but these are usually small reac- tive effusions. Most will resolve with suitable antibiotics such as a macrolide, but diagnostic pleural fluid sampling should be performed to ensure that a complicated parapneumonic effusion is not present. In all cases antibiotic regimens should be adjusted according to the results of subsequent culture results (while remembering that anaerobic pathogens are difficult to grow).

In hospital acquired empyema, usually secondary to nosocomial pneumonia, trauma or surgery, the antibiotics should be chosen to treat both Gram positive and Gram negative aerobes and also anaerobes. Postoperative and trauma related empyema requires antistaphylococcal cover. Recommended antibiotics include antipseudomonal penicillins (piperacillin-tazobactam and ticarcillin-clavulinic acid), carbapenems (meropenem), or third generation cephalosporins. ${ }^{35}$

The duration of treatment for pleural infection has not been assessed in detailed clinical trials and remains controversial. Antibiotics are often continued for several weeks, based on the experience of clinicians managing this and other purulent pulmonary diseases such as lung abscess ${ }^{3}{ }^{18}$ but, providing there is adequate pleural drainage, long term treatment may not be necessary. Treatment for about 3 weeks is probably appropriate. When prolonged treatment is used, the antibiotic regimen is usually changed to an oral combination after the fever and sepsis syndrome has settled.

Suggested antibiotic regimens for the initial treatment of culture negative community and hospital acquired pleural infections are shown in table 2 .

\subsection{Chest tube drainage}

- There is no consensus on the size of the optimal chest tube for drainage.

- If a small bore flexible catheter is used, regular flushing and suction is recommended to avoid catheter blockage. [C]

Chest tube drainage is usually performed in one of three ways: tube insertion under radiological guidance, tube insertion without radiological guidance, and tube insertion at time of surgical debridement. Traditionally, the closed chest tube drainage of pus from the pleural cavity has been via the insertion of a large bore chest tube, inserted without radiological guidance. More recently, flexible small bore catheters which seem less traumatic to insert and more comfortable for the patient have been employed. These smaller catheters are usually inserted under ultrasound or CT guidance.

There are no controlled trials comparing the use of traditional large bore chest tubes with smaller catheters and no clinical consensus on the optimal choice. Most of the published data relate to the use of image guided small bore catheters and suggest these can have a good outcome as a primary drainage procedure ${ }^{50893^{93-95}}$ or as a rescue treatment when larger tubes have failed. ${ }^{50}{ }^{89-95} 10-14$ Fr catheters are popular in these series and have a low complication rate..$^{5091-9396}$ There is 
also a substantial body of opinion that considers large bore tubes to be more effective for draining thick pus, based on clinical experience. Sound clinical trials are needed to clarify the optimal size of chest tube.

There is no controlled evidence about optimal drain management regarding issues such as drain flushing and drain suction. In most of the studies with small bore catheters, both catheter flushing and suction were used ${ }^{50}$ 89-95 $97^{97}$ and regular flushing ( $30 \mathrm{ml}$ saline every 6 hours via three-way tap) is therefore recommended for small catheters. To ensure reliability, trained nurses should ideally perform this task. Flushing larger bore drains is technically more difficult as these do not have three-way taps and disconnection for irrigation might introduce secondary infection. There are no studies to suggest any advantage from the regular flushing of large drains and it is therefore not recommended routinely. Suction $\left(20 \mathrm{~cm} \mathrm{H}_{2} \mathrm{O}\right)$ is employed in the belief it improves drainage but there is no sound evidence or clinical consensus on which to base specific guidelines in this area. ${ }^{98} 99$

\subsection{Management of cessation of chest tube drainage in the presence of a residual pleural fluid collection}

- If the chest tube becomes blocked or pus is unable to drain, it should be flushed with saline to ensure its patency. If poor drainage persists, a chest radiograph or CT scan should be performed to check drain position. [C]

In the event that the chest tube should become blocked or pus is unable to drain, it may be flushed with $20-50 \mathrm{ml}$ normal saline to ensure its patency. If poor drainage persists, imaging should be performed to check chest tube position and tube distortion and to look for undrained locules. Kinks may occur at the skin with smaller drains which can be repositioned and redressed. A number of commercial dressings are now available to secure small drains to reduce kinking and which have a low fall out rate. If the chest tube is permanently blocked, it should be removed and a further chest tube inserted if indicated.

Contrast enhanced CT scanning is the most useful imaging modality in patients failing chest tube drainage to provide anatomical detail such as locules and to ensure accurate chest tube placement. Pleural thickening seen on contrast enhanced CT scanning represents a "fibrinous" peel, which may prevent lung re-expansion despite adequate drainage of the pleural space. ${ }^{100}$ Contrast enhanced CT scanning cannot accurately differentiate early and late fibrinopurulent stage disease, ${ }^{57}$ and pleural thickness on the CT scan does not appear to predict the outcome from tube drainage. ${ }^{59}$ Pleural peel may resolve over several weeks in patients spared surgery. ${ }^{101}$ Residual calcification, ${ }^{57}$ thickening of extrapleural tissues, ${ }^{57}$ and pleural scarring ${ }^{101}$ may persist long after empyema treatment. Both ultrasound and chest radiography may also be useful in patients failing to drain.

\subsection{Intrapleural fibrinolytic drugs}

- Intrapleural fibrinolytic drugs (streptokinase 250000 IU twice daily for 3 days or urokinase 100000 IU once a day for 3 days) improve radiological outcome and current best evidence recommends their use. [B] It is not known if they reduce mortality and/or the need for surgery and clinical trials are underway to address this question.

- Patients who receive intrapleural streptokinase should be given a streptokinase exposure card and should receive urokinase or tissue plasminogen activator (TPA) for subsequent indications. [C]

Intrapleural fibrinolytic therapy was first used in $1949 .^{21}$

The agents used initially were impure and produced side effects due to immunological events such as fever, leucocytosis and general malaise, ${ }^{21}$ and these agents fell out of use. More recently, intrapleural fibrinolytic drugs have been reassessed. Several observational series suggest improved pleural drainage with these agents, ${ }^{21}{ }^{102-128}$ and these reports have been supplemented by small controlled trials. ${ }^{110}{ }^{129-132}$

There are four small randomised trials of intrapleural fibrinolytic agents. The first ${ }^{129}$ reported 24 patients randomised to streptokinase or saline placebo. Pleural drainage was improved on radiographic criteria. The study was not large enough to address surgery rates, mortality or safety. The second study ${ }^{131}$ compared urokinase and a saline placebo in 31 patients with pleural infection. Patients were randomised after failed chest tube drainage alone. Successful pleural drainage was significantly more frequent in those receiving urokinase, but again the study was not powered for mortality, surgery rates or safety. The third study ${ }^{103}$ is currently only reported in abstract form and included 128 patients with loculated parapneumonic pleural effusion randomised to receive either intrapleural urokinase, streptokinase, or control flushes. As with the other studies, ${ }^{129} 131$ groups who received fibrinolytic therapy drained more fluid and had improved radiology. The fourth study is in children and shows that urokinase reduces hospital stay compared with placebo. Again it was not powered to assess the main clinical end points of mortality and surgery frequency. ${ }^{132}$

In these studies, drained pleural fluid volume is uninterpretable since intrapleural streptokinase increases pleural fluid production. ${ }^{133}$ The current literature is therefore encouraging but does not establish benefit for the primary end points of clinical interest: patient mortality, surgery rates, and residual lung function. The Medical Research Council and British Thoracic Society are currently recruiting to a multicentre study to assess definitively the efficacy of intrapleural streptokinase.

Most reported adverse events due to intrapleural fibrinolytic agents are immunological and occur with intrapleural streptokinase. Fever has been noted, ${ }^{103}{ }^{115-117}{ }^{134}$ but only in subjects receiving fibrinolytics for pneumonia associated pleural infection where the varying fever of the primary illness makes it difficult to quantify this effect reliably. Systemically administered streptokinase generates a systemic antibody response that can neutralise later administration of streptokinase. ${ }^{135-142}$ It is not yet known whether intrapleurally administered fibrinolytic agents produce a similar response. In the absence of such data it is advisable to manage patients as if they had received their initial fibrinolytic systemically, with urokinase or tissue plasminogen activator (TPA) being used for later myocardial infarction or pulmonary embolism.

Two studies of small patient groups suggest that intrapleural streptokinase does not produce systemic fibrinolysis up to a total cumulative dose of 1.5 million IU. ${ }^{119}$ There are isolated reports of local pleural haemorrhage ${ }^{106112116}$ and systemic bleeding ${ }^{118}$ associated with intrapleural fibrinolytic use. There have also been reports of nose bleeds, ${ }^{116}$ pleural pain, ${ }^{109} 116121$ and transient disorientation (without evidence of intracerebral bleeding on CT brain scan). ${ }^{109}$ Urokinase is non-antigenic but may still cause acute reactions (due to immediate hypersensitivity and histamine release) with fever ${ }^{124}$ and cardiac arrhythmia. ${ }^{143}$ There is a report of adult respiratory distress syndrome (ARDS) in a patient who received both streptokinase and urokinase for empyema drainage. ${ }^{144}$ The true incidence of these occasional but major side effects is not known and will be clarified by the currently recruiting MRC/ BTS trial.

Streptokinase 250000 IU daily, ${ }^{21} 103-119121129$ or 250000 IU 12 hourly, ${ }_{119}^{19}$ or urokinase $100000 \mathrm{U}$ daily ${ }^{131}{ }^{134}$ retained for 2-4 hours in the pleural space are the usual regimens. Their use may be most beneficial in high risk patients of an older age or with co-morbidity where surgery has a greater risk.

Recently, there has been interest in other intrapleural agents including combination drugs consisting of streptokinase and streptodornase- $\alpha$, DNase. ${ }^{145}{ }^{146}$ In an experimental 
setting in which fluid viscosity was assessed, this combination reduced the amount of non-liquefied material and therefore viscosity compared with streptokinase alone. ${ }^{145} 146$ These in vitro studies suggest that it is the DNA content of pus that determines the viscosity and that, if it is effective, streptokinase may work predominantly by breaking down loculations and not by changing pus viscosity. Clinical trials will be required to assess whether DNase compounds are effective adjuncts in pleural drainage, and their use in patients cannot yet be recommended.

\subsection{Persistent sepsis and pleural collection}

- Patients with persistent sepsis and a residual pleural collection should undergo further radiological imaging. $[\mathrm{C}]$

In patients who do not respond to medical treatment and who have sepsis in association with a persistent pleural collection, the diagnosis should be reviewed and a further chest radiograph performed. Thoracic CT scanning will identify chest tube position, pleural thickening, and anatomy of the effusion, and may also identify endobronchial obstruction of the bronchi by malignancy ${ }^{147-150}$ or foreign body, and pathology in the mediastinum when there is inadequate resolution of pleural sepsis following drainage.

\subsection{Bronchoscopy}

- Bronchoscopy should only be performed in patients where there is a high index of suspicion of bronchial obstruction. [C]

The role of bronchoscopy in patients with empyema has not been addressed specifically by any studies, but it is clear from the BTS empyema series ${ }^{4}$ that British chest physicians consider bronchoscopy an important investigation in patients with pleural infection. In this series, ${ }^{4} 43$ of 119 patients (40\%) underwent bronchoscopy, usually to exclude a tumour predisposing to empyema; tumour was only found in five patients, less than $4 \%$ of the total sample. Bronchoscopy is usually performed at the time of surgery by most thoracic surgeons, but only a small number of these patients have obstructing tumour predisposing to empyema. ${ }^{43}$ In view of the small number of patients in whom bronchoscopy is helpful, it is only recommended where there is a high index of suspicion for bronchial obstruction. Features that should raise this suspicion include a mass or loss of volume on radiographic imaging or a history of possible aspiration/inhalation.

\subsection{Nutrition}

- Clinicians should ensure adequate nutritional support commencing as soon as possible after pleural infection is identified. [C]

Poor nutrition was identified during the First World War as one of the important determinants of outcome from pleural empyema, ${ }^{16}$ but is still sometimes overlooked. Patients with empyema suffer the catabolic consequences of chronic infection which may lead to further immunodeficiency and slow recovery. Clinicians should provide adequate nutritional support from the time the diagnosis is made. Hypoalbuminaemia is associated with a poor outcome from pleural infection. ${ }^{4}$

\subsection{Referral for surgical treatment}

- Failure of chest tube drainage, antibiotics and fibrinolytic drugs should prompt early discussion with a thoracic surgeon. [C]

- Patients should be considered for surgical treatment if they have persisting sepsis in association with a persistent pleural collection, despite chest tube drainage and antibiotics. [C]

\section{Audit points}

- Pleural fluid should be sampled for diagnostic purposes within 24 hours in over $95 \%$ of cases of suspected pleural infection.

- Pleural fluid pH should be measured with a blood gas analyser at the first diagnostic pleural fluid tap in all cases unless the pleural fluid sample is visibly purulent.

- All pleural fluid samples assessed in a blood gas analyser must be heparinised.

- All patients treated for pleural infection should receive appropriate antibiotic treatment.

- Unless there is a clear contraindication to chest drainage, all pleural effusions being treated as infected should be drained by a chest tube.

- All patients should have had an assessment of the effectiveness of the drainage of the pleural fluid collection and the resolution of their fever and sepsis 5-8 days after starting chest tube drainage and antibiotics for pleural infection. The result of this assessment should be recorded in the clinical notes.

- All patients who have not achieved effective pleural drainage at the outcome assessment described above should be discussed with a thoracic surgeon to consider surgical drainage of the infected collection.

The decision to operate to achieve empyema drainage is subjective, and there are no established objective criteria to define the point at which a patient should proceed to surgery. Patients with purulent fluid ${ }^{59}$ and/or loculations ${ }^{69}$ at presentation are more likely to require surgical drainage, although many patients settle without surgery. Patients should be considered for surgery if they have a residual sepsis syndrome in association with a persistent pleural collection, despite drainage and antibiotics. Failure of sepsis to begin resolution within 7 days $^{45151}$ is suggested as an appropriate period after which a surgical opinion should be sought.

A number of surgical approaches are available including video assisted thoracoscopic surgery (VATS), open thoracic drainage, or thoracotomy and decortication. The type of procedure performed will depend on many factors including patient age and co-morbidity, and surgical preference including the local availability of video assisted surgical techniques. The choice of surgical procedure is beyond the remit of these guidelines and is not considered further.

One small trial has directly compared surgical and medical treatment. Wait et al ${ }^{9}$ randomised 20 patients with pleural infection who were suitable for general anaesthesia to receive immediate VATS or intrapleural streptokinase for 3 days instilled into a chest tube. Chest tubes were not inserted under radiological guidance in the medical group and were inserted by junior resident medical staff. The surgical group had higher primary treatment success (10/11 patients) and all medical failures (5/9 patients) were salvaged by surgery without requiring thoracotomy. Surgical patients required shorter drainage time ( $5.8 v 9.8$ days $)$ and had a shorter stay in hospital ( $8.7 v 12.8$ days). The results of this study need to be interpreted in the light of the small sample size and the unusually high failure rate in the control limb (55\%). Further appropriately powered studies are needed.

2.16 Patients not considered fit for surgery and not improving with chest tube drainage and antibiotics

- In cases of ineffective chest tube drainage and persistent sepsis in patients unable to tolerate general anaesthesia, re-imaging the thorax and placement of further image guided small bore catheters, large bore chest tubes, or intrapleural fibrinolytic therapy should be considered. [C] 


\section{- Local anaesthetic surgical rib resection should be considered in patients unsuitable for general anaes- thesia. $[\mathrm{C}]$}

Ineffective chest tube drainage and persistent sepsis in patients unfit for general anaesthesia can be approached by a number of "less invasive" options. Re-imaging the thorax and placement of further image guided small bore catheters may drain loculated collection s $^{509-919394}$ and large bore chest tubes can be tried for "thick" pus. ${ }^{96}$ Alternatively, patients may proceed to surgical rib resection and open drainage under local anaesthesia.

\section{Authors' affiliations}

C W H Davies, Department of Respiratory Medicine, Battle and Royal Berkshire Hospitals, Oxford Road, Reading RG30 1AG, UK F V Gleeson, Department of Radiology, Churchill Hospital Site, Oxford Radcliffe Hospital, Headington, Oxford OX3 7L, UK

R J O Davies, Oxford Centre for Respiratory Medicine, Churchill Hospital Site, Oxford Radcliffe Hospital, Headington, Oxford OX3 7L, UK

\section{REFERENCES}

1 Berger HA, Morganroth ML. Immediate drainage is not required for all patients with complicated parapneumonic effusions. Chest 1990:97:731-5. [III]

2 Strange C, Sahn SA. The clinician's perspective on parapneumonic effusions and empyema. Chest 1993;103:259-61. [IIb]

3 Sahn SA. Management of complicated parapneumonic effusions. Am Rev Respir Dis 1993;148:813-7. [IV]

4 Ferguson AD, Prescott RJ, Selkon JB, et al. Empyema subcommittee of the Research Committee of the British Thoracic Society. The clinical course and management of thoracic empyema. Q J Med 1996;89:285-9. [III]

5 Heffner JE, McDonald J, Barbieri C, et al. Management of parapneumonic effusions. An analysis of physician practice patterns. Arch Surg 1995;130:433-8. [III]

6 Light RW, MacGregor MI, Ball WCJ, et al. Diagnostic significance of pleural fluid $\mathrm{pH}$ and $\mathrm{PCO}_{2}$. Chest 1973;64:591-6. [IIb]

7 Matsumoto AH. Image guided drainage of complicated pleural effusions and adjunctive use of intrapleural urokinase. Chest 1995; 108:1190-1. [III]

8 Parmar JM. How to insert a chest drain. Br J Hosp Med 1989;42:23 1-3. [IV]

9 Wait MA, Sharma S, Hohn J, et al. A randomized trial of empyema therapy. Chest 1997;111:1548-51. [Ib]

10 LeMense GP, Strange C, Sahn SA. Empyema thoracis. Therapeutic management and outcome. Chest 1995;107:1532-7. [III]

11 Storm HK, Krasnik M, Bang K, et al. Treatment of pleural empyema secondary to pneumonia: thoracocentesis regimen versus tube drainage. Thorax 1992;47:821-4. [III]

12 Mackenzie JW. Video-assisted thoracoscopy: treatment for empyema and hemothorax. Chest 1996;109:2-3. [IV]

13 Galea JL, De Souza A, Beggs D, et al. The surgical management of empyema thoracis. J R. Coll Surg Edinb 1997;42:15-18. [III]

14 Wallenhaupt SL. Surgical management of thoracic empyema. J Thorac Imaging 1991;6:80-8. [III]

15 Meyer JA. Gotthard Bulau and closed water-seal drainage for empyema, 1875-1891. Ann Thorac Surg 1989;48:597-9. [IV]

16 Peters RM. Empyema thoracis: historical perspective. Ann Thorac Surg 1989;48:306-8. [IV]

17 Heffner JE. Diagnosis and management of thoracic empyemas. Curr Opin Pulmon Med 1996;2:198-205. [IV]

18 Bartlett JG. Anaerobic bacterial infections of the lung and pleural space. Clin Infect Dis 1993;16(Suppl 4):S248-55. [IV]

19 Stiles QR, Lindesmith GG, Tucker BL, et al. Pleural empyema in children. Ann Thorac Surg 1970;10:37-44. [III]

20 Alfageme I, Munoz F, Pena $N$, et al. Empyema of the thorax in adults. Etiology, microbiologic findings, and management. Chest 1993; 103:839-43. [III]

21 Tillett WS, Sherry S. The effect in patients of streptococcal fibrinolysin (streptokinase) and streptococcal desoxyribonuclease on fibrinous, purulent, and sanguinous pleural exudations. J Clin Invest 1949;28:173-90. [III]

22 Macfarlane JT. Pneumonia and other acute infections: acute respiratory infections in adults. In: Brewis RAL, Corrin B, Geddes DM, Gibson GJ eds. Respiratory medicine. London: W B Saunders, 1995: 705-46. [IV]

23 Taryle DA, Potts DE, Sahn SA. The incidence and clinical correlates of parapneumonic effusions in pneumococcal pneumonia. Chest 1978;74:170-3. [III]

24 Light RW, Girard WM, Jenkinson SG, et al. Parapneumonic effusions. Am J Med 1980;69:507-12. [IIb]
25 Wang N. Anatomy of the pleura. Clin Chest Med 1998;19:229-40. [IV]

26 Agostini E, Zocchi L. Mechanical coupling and liquid exchanges in the pleural space. Clin Chest Med 1998;19:241-60. [IV]

27 American Thoracic Society. Management of nontuberculous empyema: a statement of the subcommittee on surgery. Am Rev Respir Dis 1962;935-6. [IV]

28 Kroegel C, Anthony VB. Immunobiology of pleural inflammation: potential implications for pathogenesis, diagnosis and therapy. Eur Respir J 1997;10:2411-8. [IV]

29 Good JT Jr, Taryle DA, Maulitz RM, et al. The diagnostic value of pleural fluid $\mathrm{pH}$. Chest 1980;78:55-9. [III]

30 Sasse SA, Causing LA, Mulligan ME, et al. Serial pleural fluid analysis in a new experimental model of empyema. Chest 1996;109:1043-8. [IIb]

31 Potts DE, Taryle DA, Sahn SA. The glucose-pH relationship in parapneumonic effusions. Arch Intern Med 1978;138:1378-80. [IIb]

32 Potts DE, Levin DC, Sahn SA. Pleural fluid $\mathrm{pH}$ in parapneumonic effusions. Chest 1976;70:328-31. [IIb]

33 Idell S, Girard W, Koenig KB, et al. Abnormalities of pathways of fibrin turnover in the human pleural space. Am Rev Respir Dis 1991;144:187-94. [IIb]

34 Sahn SA, Reller LB, Taryle DA, et al. The contribution of leukocytes and bacteria to the low $\mathrm{pH}$ of empyema fluid. Am Rev Respir Dis 1983;128:811-5. [IIb]

35 Hughes CE, Van Scoy RE. Antibiotic therapy of pleural empyema. Semin Respir Infect 1991:6:94-102. [IV]

36 Bartlett JG, Gorbach SL, Thadepalli H, et al. Bacteriology of empyema. Lancet 1974;338-40. [III]

37 Brook I, Frazier EH. Aerobic and anaerobic microbiology of empyema: a retrospective review in two military hospitals. Chest 1993;103:1502 7. [III]

38 Ashbaugh DG. Empyema thoracis. Factors influencing morbidity and mortality. Chest 1991;99:1162-5. [III]

39 Landreneau RJ, Keenan RJ, Hazelrigg SR, et al. Thoracoscopy for empyema and hemothorax. Chest 1996;109:18-24. [III]

40 Varkey B, Rose HD, Kutty CP, et al. Empyema thoracis during a ten-year period. Analysis of 72 cases and comparison to a previous study (1952 to 1967). Arch Intern Med 1981;141:1771-6. [III]

41 Ali I, Unruh H. Management of empyema thoracis. Ann Thorac Surg 1990;50:355-9. [III]

42 Smith JA, Mullerworth MH, Westlake GW, et al. Empyema thoracis: 14-year experience in a teaching center. Ann Thorac Surg 1991;51:39-42. [III]

43 Sherman MM, Subramanian V, Berger RL. Management of thoracic empyema. Am J Surg 1977;133:474-9. [III]

44 Mandal AK, Thadepalli H. Treatment of spontaneous bacterial empyema thoracis. J Thorac Cardiovasc Surg 1987;94:414-8. [III]

45 Mavroudis C, Symmonds JB, Minagi H, et al. Improved survival in management of empyema thoracis. J Thorac Cardiovasc Surg $1981 ; 82: 49-57$. [III]

46 Van Way C3, Narrod J, Hopeman A. The role of early limited thoracotomy in the treatment of empyema. J Thorac Cardiovasc Surg 1988;96:436-9. [III]

47 Lemmer JH, Botham M, Orringer MB. Modern management of adult thoracic empyema. J Thorac Cardiovasc Surg 1985;90:849-55. [III]

48 Lawrence DR, Ohri SK, Moxon RE, et al. Thoracoscopic debridement of empyema thoracis. Ann Thorac Surg 1997;64:1448-50. [III]

49 Civen R, Jousimies-Somer H, Marina $M$, et al. A retrospective review of cases of anaerobic empyema amd update of bacteriology. Clin Infect Dis 1995;20(Suppl):S224-9. [III]

50 Stavas J, van Sonnenberg E, Casola G, et al. Percutaneous drainage of infected and noninfected thoracic fluid collections. J Thorac Imaging 1987;2:80-7. [IV]

51 Eibenberger KL, Dock WI, Ammann ME, et al. Quantification of pleural effusions: sonography versus radiography. Radiology 1994;191:681-4. [IIb]

52 Yang PC, Luh KT, Chang DB, et al. Value of sonography in determining the nature of pleural effusion: analysis of 320 cases. ANR 1992;159:29-33. [III]

53 Kearney SE, Davies CW, Davies R, et al. Computerised tomography and ultrasound correlation in parapneumonic effusions and empyema. Clin Radiol 2000;55:542-7. [III]

54 Stark DD, Federle MP, Goodman PC, et al. Differentiating lung abscess and empyema: radiography and computed tomography. AJR 1983;141:163-7. [III]

55 Muller NL. Imaging of the pleura. Radiology 1993;186:297-309. [IV]

56 Aquino SL, Webb WR, Gushiken BJ. Pleural exudates and transudates: diagnosis with contrast-enhanced CT. Radiology 1994;192:803-8. [III]

57 Waite RJ, Carbonneau RJ, Balikian JP, et al. Parietal pleural changes in empyema: appearances at CT. Radiology 1990;175:145-50. [III]

58 Takasugi JE, Godwin JD, Teefey SA. The extrapleural fat in empyema: CT appearance. Br J Radiol 1991;64:580-3. [III]

59 Davies CWH, Kearney SE, Gleeson FV, et al. Predictors of outcome and long term survival in patients with pleural infection. Am J Respir Crit Care Med 1999;160:1682-7. [III]

60 Poe RH, Marin MG, Israel RH, et al. Utility of pleural fluid analysis in predicting tube thoracostomy/decortication in parapneumonic effusions. Chest 1991;100:963-7. [III]

61 Himelman RB, Callen PW. The prognostic value of loculations in parapneumonic pleural effusions. Chest 1986;90:852-6. [III]

62 Light RW. A new classification of parapneumonic effusions and empyema. Chest 1995;108:299-301. [IV] 
63 Heffner JE, Brown LK, Barbieri C, et al. Pleural fluid chemical analysis in parapneumonic effusions. A meta-analysis. Am J Respir Crit Care Med 1995; 151:1700-8. [la]

64 Mattison LE, Coppage L, Alderman DF, et al. Pleural effusions in the medical ICU: prevalence, causes, and clinical implications. Chest 1997;111:1018-23. [III]

65 Hamm H, Light RW. Parapneumonic effusion and empyema. Eur Respir J 1997; 10:1150-6. [IV]

66 Lesho EP, Roth BJ. Is $\mathrm{pH}$ paper an acceptable, low-cost alternative to the blood gas analyzer for determining pleural fluid $\mathrm{pH}$ ? Chest

1997:112:1291-2. [IIa]

67 Cheng D, Rodriguez M, Rogers J, et al. Comparison of pleural fluid pH values obtained using blood gas machine, $\mathrm{pH}$ meter, and $\mathrm{pH}$ indicator strip. Chest 1998;114:1368-72. [IIa]

68 Jimenez-Castro D, Diaz G, Perez-Rodriguez E, et al. Modification of pleural fluid pH by local anaesthesia. Chest 1999;1 16:399-402. [IIa]

69 Huang HC, Chang HY, Chen CW, et al. Predicting factors for outcome of tube thoracostomy in complicated parapneumonic effusion or empyema. Chest 1999;115:751-6. [III]

70 Cham CW, Haq SM, Rahamim J. Empyema thoracis: a problem with late referral? Thorax 1993;48:925-7. [IV]

71 Sasse S, Nguyen TK, Mulligan M, et al. The effects of early chest tube placement on empyema resolution. Chest 1997;111:1679-83. [lb]

72 Neild JE, Eykyn SJ, Phillips I. Lung abscess and empyema. Q J Med 1985;57:875-82. [III]

73 Bartlett JG. Antibiotics in lung abscess. Semin Respir Infect 1991;6:103-11. [IV]

74 Minton EJ, Macfarlane JT. Antibiotic resistant Streptococcus pneumoniae. Thorax 1996;51 (Suppl 2):S45-50. [IV]

75 Wong CA, Donald F, Macfarlane JT. Streptococcus milleri pulmonary disease: a review and clinical description of 25 patients. Thorax 1995;50:1093-6. [III]

76 Jerng JS, Hsueh PR, Teng $L$, et al. Empyema thoracis and lung abscess caused by viridans streptococci. Am J Respir Crit Care Med 1997; 156:1508-14. [III]

77 Taryle DA, Good JT, Morgan EJ, et al. Antibiotic concentrations in human parapneumonic effusions. Antimicrob Agents Chemother 1981;7:171-7. [IIlb]

78 Scaglione F. Serum protein binding and extravascular diffusion of methoxyimino cephalosporins. Time courses of cefotaxime and ceftriaxone in serum and pleural exudate. J Antimicrob Agents Chemother 1990;26(Suppl A): 1-10. [IIb]

79 Shohet I, Yellin A, Meyerovitch J, et al. Pharmacokinetics and therapeutic efficacy of gentamicin in an experimental pleural empyema rabbit model. Antimicrob Agents Chemother 1987;31:982-5. [IIb]

80 Huchon G, Woodhead M. Guidelines for management of adult community-acquired lower respiratory tract infections. European Study on Community-acquired Pneumonia (ESOCAP) Committee. Eur Respir J 1998;11:986-91. [IV]

81 Hammond JM, Potgieter PD, Hanslo D, et al. The etiology and antimicrobial susceptibility patterns of microorganisms in acute community-acquired lung abscess. Chest 1995; 108:937-41. [III]

82 Shinzato T, Saito A. A mechanism of pathogenicity of "Streptococcus milleri group" in pulmonary infection: synergy with an anaerobe. J Med Microbiol 1994;40:118-23. [IIb]

83 Shinzato T, Saito A. The Streptococcus milleri group as a cause of pulmonary infections. Clin Infect Dis 1995;21 (Suppl 3):S238-43. [III]

84 Finegold SM, Wexler HM. Present studies of therapy for anaerobic infections. Clin Infect Dis 1996;23(Suppl 1):S9-14. [IV]

85 Kroboth FJ. Clinicoradiographic correlation with extent of Legionnaires disease. AJR 1983;141:263-8. [IIb]

86 Randolph KA. Legionnaires' disease presenting with empyema. Chest 1979;75:404-6. [III]

87 Fine NL, Smith LR, Sheedy PF. Frequency of pleural effusions in mycoplasma and viral pneumonias. N Engl J Med 1970;283:790-3. [III]

88 Mansel JK, Rosenow ECl, Smith TF, et al. Mycoplasma pneumoniae pneumonia. Chest 1989;95:639-46. [III]

89 Silverman SG, Mueller PR, Saini S, et al. Thoracic empyema: management with image-guided catheter drainage. Radiology 1988;169:5-9. [III]

90 Crouch JD, Keagy BA, Delany DJ. "Pigtail" catheter drainage in thoracic surgery. Am Rev Respir Dis 1987;136:174-5. [III]

91 van Sonnenberg E, Nakamoto SK, Mueller PR, et al. CT- and ultrasound-guided catheter drainage of empyemas after chest-tube failure. Radiology 1984;151:349-53. [III]

92 Hunnam GR, Flower CD. Radiologically-guided percutaneous catheter drainage of empyemas. Clin Radiol 1988;39:121-6. [III]

93 Ulmer JL, Choplin RH, Reed JC. Image-guided catheter drainage of the infected pleural space. J Thorac Imaging 1991;6:65-73. [IV]

94 Westcott JL. Percutaneous catheter drainage of pleural effusion and empyema. AVR 1985;144:1189-93. [III]

95 Merriam MA, Cronan JJ, Dorfman GS, et al. Radiographically guided percutaneous catheter drainage of pleural fluid collections. AJR 1988;151:1113-6. [III]

96 Klein JS, Schultz S, Heffner JE. Interventional radiology of the chest: image-guided percutaneous drainage of pleural effusions, lung abscess, and pneumothorax. AJR 1995;164:581-8. [IV]

97 Lee KS, Im JG, Kim YH, et al. Treatment of thoracic multiloculated empyemas with intracavitary urokinase: a prospective study. Radiology $1991 ; 179: 771-5$. [III]

98 Munnell ER. Thoracic drainage. Ann Thorac Surg 1997;63:1497-502 [IV]
99 Miller KS, Sahn SA. Chest tubes. Indications, technique, management and complications. Chest 1987;91:258-64. [IV]

100 Moulton AL. Surgical definition of pleural peel. Radiology $1991 ; 178: 889-900$. [IV]

101 Neff CC, van Sonnenberg E, Lawson DW, et al. CT follow-up of empyemas: pleural peels resolve after percutaneous catheter drainage. Radiology 1990;176:195-7. [III]

102 Robinson LA, Moulton AL, Fleming WH, et al. Intrapleural fibrinolytic treatment of multiloculated thoracic empyemas. Ann Thorac Surg 1994;57:803-13. [III]

103 Bilaceroglu.S, Cagerici.U, Cakan A. Management of complicated parapneumonic pleural effusions with image-guided drainage and intrapleural urokinase or streptokinase: a controlled randomized trial. Eur Respir J 1997; 10:325S. [Ib]

104 Henke CA, Leatherman JW. Intrapleurally administered streptokinase in the treatment of acute loculated nonpurulent parapneumonic effusions. Am Rev Respir Dis 1992;145:680-4. [III]

105 Aye RW, Froese DP, Hill LD. Use of purified streptokinase in empyema and hemothorax. Am J Surg 1991;161:560-2. [III]

106 Temes RT, Follis F, Kessler RM, et al. Intrapleural fibrinolytics in management of empyema thoracis. Chest 1996:110:102-6. [III]

107 Ogirala RG, Williams MHJ. Streptokinase in a loculated pleural effusion. Effectiveness determined by site of instillation. Chest 1988;94:884-6. [III]

108 Willsie Ediger SK, Salzman G, Reisz G, et al. Use of intrapleural streptokinase in the treatment of thoracic empyema. Am J Med Sci 1990;300:296-300. [III]

109 Jeries Sanchez C, Ramirez Rivera A, Elizalde JJ, et al. Intrapleural fibrinolysis with streptokinase as an adjunctive treatment in hemothorax and empyema: a multicenter trial. Chest 1996;109:1514-9. [III]

110 Chin NK, Lim TK. Controlled trial of intrapleural streptokinase in the treatment of pleural empyema and complicated parapneumonic effusions. Chest 1997;111:275-9. [IIa]

111 Fraedrich G, Hofmann D, Effenhauser P, et al. Instillation of fibrinolytic enzymes in the treatment of pleural empyema. Thorac Cardiovasc Surg 1982:30:36-8. [III]

112 Porter J, Banning AP. Intrapleural streptokinase. Thorax 1998;53:720. [III]

113 Taylor RFH, Rubens MB, Pearson MC, et al. Intrapleural streptokinase in the management of empyema. Thorax 1994;49:856-9. [III]

114 Mitchell ME, Alberts WM, Chandler KW, et al. Intrapleural streptokinase in management of parapneumonic effusions. Report of series and review of literature. J Fla Med Assoc 1989;76:1019-22. [III]

115 Roupie E, Bouabdallah K, Delclaux C, et al. Intrapleural administration of streptokinase in complicated purulent pleural effusion: a CT-guided strategy. Intensive Care Med 1996;22:1351-3. [III]

116 Laisaar T, Puttsepp E, Laisaar V. Early administration of intrapleural streptokinase in the treatment of multiloculated pleural effusions and pleural empyemas. Thorac Cardiovasc Surg 1996;44:252-6. [III]

117 Bouros D, Schiza S, Panagou P, et al. Role of streptokinase in the treatment of acute loculated parapneumonic pleural effusions and empyema. Thorax 1994;49:852-5. [III]

118 Godley PJ, Bell RC. Major hemorrhage following administration of intrapleural streptokinase. Chest 1984;86:486-7. [III]

119 Davies CWH, Lok S, Davies RJ. The systemic fibrinolytic activity of intrapleural streptokinase. Am J Respir Crit Care Med 1998;157:328 30. [IIb]

120 Bergh NP, Ekroth R, Larsson S, et al. Intrapleural streptokinase in the treatment of haemothorax and empyema. Scand J Thorac Cardiovasc Surg 1977;11:265-8. [III]

121 Berglin E, Ekroth R, Teger Nilsson AC, et al. Intrapleural instillation of streptokinase. Effects on systemic fibrinolysis. Thorac Cardiovasc Surg 1981;29:124-6. [IIb]

122 Ryan JM, Boland GW, Lee M, et al. Intracavitary urokinase therapy as an adjunct to percutaneous drainage in a patient with a multiloculated empyema. AJR 1996;167:643-7. [III]

123 Park CS, Chung WM, Lim MK, et al. Transcatheter instillation of urokinase into loculated pleural effusion: analysis of treatment effect. AVR 1996; 167:649-52. [III]

124 Cohen ML, Finch IJ. Transcatheter intrapleural urokinase for loculated pleural effusion. Chest 1994:105:1874-6. [III]

125 Pollak JS, Passik CS. Intrapleural urokinase in the treatment of loculated pleural effusions. Chest 1994;105:868-73. [III]

126 Bouros D, Schiza S, Tzanakis N, et al. Intrapleural urokinase in the treatment of complicated parapneumonic pleural effusions and empyema. Eur Respir J 1996;9:1656-9. [III]

127 Moulton JS, Benkert RE, Weisiger KH, et al. Treatment of complicated pleural fluid collections with image- guided drainage and intracavitary urokinase. Chest 1995;108:1252-9. [III]

128 Moulton JS, Moore PT, Mencini RA. Treatment of loculated pleural effusions with transcatheter intracavitary urokinase. AJR 1989;153:941-5. [III]

129 Davies RJO, Traill ZC, Gleeson FV. Randomised controlled trial of intra-pleural streptokinase in community acquired pleural infection. Thorax 1997;52:416-21. [lb]

130 Bouros D, Schiza S, Patsourakis G, et al. Intrapleural streptokinase versus urokinase in the treatment of complicated parapneumonic effusions: a prospective, double-blind study. Am J Respir Crit Care Med 1997;155:291-5. [lb]

131 Bouros D Schiza S, Tzanakis N, et al. Intrapleural urokinase versus normal saline in the treatment of complicated parapneumonic effusions and empyema. Am J Respir Crit Care Med 1999;159:37-42. [Ib] 
132 Thomson $\mathbf{A H}, \mathrm{Hull} J$, Kumar $\mathrm{R}$ et al. A randomised trial of intrapleural urokinase in the treatment of childhood empyema. Thorax 2002; 57; 343-7. [lb]

133 Strange C, Allen ML, Harley R, et al. Intrapleural streptokinase in experimental empyema. Am Rev Respir Dis 1993;147:962-6. [IIb]

134 Bouros D, Schiza S, Patsourakis G, et al. Intrapleural streptokinase versus urokinase in the treatment of complicated parapneumonic effusions. Am J Respir Crit Care Med 1997;155:291-5. [lb]

135 Jennings K. Antibodies to streptokinase. BM 1996;312:393-4. [IV]

136 Lynch M, Littler WA, Pentecost BL, et al. Immunoglobulin response to intravenous streptokinase in acute myocardial infarction. Br Heart J 1991;66:139-42. [IIb]

137 Patel S, Jalihal S, Dutka DP, et al. Streptokinase neutralisation titres up to 866 days after intravenous streptokinase for acute myocardial infarction. Br Heart J 1993;70: 119-21. [III]

138 Jalihal S, Morris GK. Antistreptokinase titres after intravenous streptokinase. Lancet 1990;335:184-5. [IIb]

139 Elliott JM, Cross DB, Cederholm Williams SA, et al. Neutralizing antibodies to streptokinase four years after intravenous thrombolytic therapy. Am J Cardiol 1993;71:640-5. [Ilb]

140 Buchalter MB, Suntharalingam G, Jennings I, et al. Streptokinase resistance: when might streptokinase administration be ineffective? $\mathrm{Br}$ Heart J 1992;68:449-53. [IIb]

141 Fears R, Ferres H, Glasgow E, et al. Monitoring of streptokinase resistance titre in acute myocardial infarction patients up to 30 months after giving streptokinase or anistreplase and related studies to measure specific antistreptokinase lgG. Br Heart J 1992;68:167-70. [IIb]
142 Lee HS Cross S, Davidson R, et al. Raised levels of antistreptokinase antibody and neutralization titres from 4 days to 54 months after administration of streptokinase or anistreplase. Eur Heart J 1993; 14:84-9. [IIb]

143 Alfageme I, Vazquez R. Ventricular fibrillation after intrapleural urokinase. Intensive Care Med 1997;23:352. [III]

144 Frye MD, Jarratt M, Sahn SA. Acute hypoxemic respiratory failure following intrapleural thrombolytic therapy for hemothorax. Chest 1994;105:1595-6. [III]

145 Light RW, Nguyen T, Mulligan ME, et al. The in vitro efficacy of varidase versus streptokinase or urokinase for liquefying thick purulent exudative material from loculated empyema. Lung 2000;178:13-18. [IIb]

146 Simpson G, Roomes D, Heron M. Effects of streptokinase and deoxyribonuclease on viscosity of human surgical and empyema pus. Chest 2000;117:1728-33. [ilb]

147 Naidich DP, Lee JJ, Garay SM, et al. Comparison of CT and fiberoptic bronchoscopy in the evaluation of bronchial disease. AUR 1987; 148: 1-7. [IIlb]

148 Naidich DP, Harkin TJ. Airways and lung: correlation of CT with fiberoptic bronchoscopy. Radiology 1995;197:1-12. [IIb]

149 Millar AB, Boothroyd AE, Edwards D, et al. The role of computed tomography (CT) in the investigation of unexplained haemoptysis. Respir Med 1992;86:39-44. [III]

150 Woodring JH. Determining the cause of pulmonary atelectasis: a comparison of plain radiography and CT. AJR 1988;150:757-63. [III]

151 Pothula V, Krellenstein DJ. Early aggressive surgical management of parapneumonic empyemas. Chest 1994;105:832-6. [III] 